\title{
FORESTS AND PEOPLE*
}

\author{
Samuel T. Dana \\ Dean, School of Forestry and Conservation, \\ University of Michigan, Ann Arbor, Mishigan
}

The close relationship that exists between forests and people is one that I should like to present by a few specific examples rather than in glittering generalities. I hope that you will pardon me if I use the first person rather freely in doing so. Suppose we start with a chapter out of my daily life.

I live in what looks like a brick house, but actually its frame is constructed almost entirely of wood. I slept last night in a wooden bed. When I woke this morning, I looked at a wall covered with paper made from wood pulp, and at pictures framed in wood and hung from a wooden molding. The paint on the wooden door which I opened on my way to the bathroom contained turpentine from a southern pine tree and oil from a tung tree. My socks and ties were made of rayon that originated in a spruce forest. The leather in my shoes was tanned with an extract from oak bark.

I walked to the dining room on wooden stairs and wooden floors, and ate my breakfast sitting in a wooden chair at a wooden table. My orange came from a wooden crate, my cereal from a paperboard container, my drink from a coffee tree, my sugar from a maple, and my paper napkin from an aspen. The newspaper that I read, except for the ink, was almost entirely a product of the forest. The plastic ash tray at my elbow consisted largely of wood flour, as did also the linoleum which I presently swept with a wooden-handled broom. Even the soap with which I washed the dishes contained rosin from the same kind of pine that produced the turpentine for the paint.

At my office I sat in a wooden chair at a wooden desk; read documents from wooden file cases; wrote with a wooden pencil on paper made from wood pulp; and dictated to a stenographer in a rayon dress. On my way to Detroit I saw freight cars made partly of wood running on wooden railroad ties. I passed hundreds of poles carrying wires for the transmission of power and of telephone and telegraph messages. The older tires on my automobile were made of natural rubber from a rubber tree, while the newer ones were made of synthetic rubber manufac-

* Delivered at the meeting of the Central Association of Science and Mathematics Teachers, Detroit, Michigan, November 30, 1946. 
tured from alcohol produced by fermentation of sugar that had once been cellulose in a Douglas fir tree. The milk shake that I had on my arrival was flavored with vanillin made from the waste liquor at a wood-pulp plant.

This sketchy list of some of the ways in which one person has come into contact with products of the forest in the course of a few hours will perhaps illustrate sufficiently one of the relationships between forests and people. We hear much of the substitution of other matcrials for wood; yet wood is not only holding its own for many purposes but is constantly finding new uses. So diversified are the uses to which it may be put that the Germans have dubbed it "Universalrohstoff" - the universal raw material. Whoever we are, and whatever we do, the products of the forest enter into our daily lives in innumerable ways, some obvious, others generally unsuspected.

In addition to the contributions which they make to our personal comfort, the forests are the basis for much of our industrial activity. It may surprise you to know that the woodusing industries rank high among all manufacturing industries in number of establishments, number of men employed, wages paid, and value of products. They provide widespread opportunity for the profitable employment of labor and capital, and are the chief source of prosperity for many a community. That prosperity may, however, be short-lived unless the forests are so managed as to maintain a continuing flow of raw material for industrial use. Let me illustrate this fact by a true story.

Fifty years ago a primeval forest of hemlock and hardwoods covered much of north-central Pennsylvania. Part of this, known as the "Black Forest," was so dense that the reading of a newspaper in its shade at high noon was said to be difficult. Here in 1895 the Lackawanna Lumber Company started logging and milling operations. Almost overnight these resulted in the appearance in the hitherto unbroken wilderness of the hustling town of Cross Fork.

The main support of the town was the big sawmill, ' which burned down twice, to be replaced each time by a bigger, busier, and better mill. In its final form it turned out approximately 72 million board feet of lumber a year with a value of about a million dollars. Smaller industrial establishments included a planing mill, lath mill, kindling mill, shingle mill, hub factory and machine shops.

Cross Fork itself rapidly expanded to a population of some 
2500 persons, with an additional 5000 lumberjacks in the neighboring woods. The general store run by the Lackawanna Lumber Company had a larger trade than any other store in the county. Yet it had plenty of competition for there were also five independent groceries, a dry-goods shop, a millinery shop, two clothing stores, a shoe store, two drug stores, a hardware store, a sporting goods store, and numerous other retail establishments. There were three doctors, a dentist, and two undertakers. Seven hotels offered welcome to the traveler, while three restaurants, one of which advertised to purvey anything that Delmonico's did, ministered to the inner man. The town's religious, educational, and social needs were met by four churches, a W.C.T.U., a Y.M.C.A., an exceptionally fine high school and grade school, several fraternal organizations, an opera house, and a weekly newspaper.

But the forests on which all this activity depended were not inexhaustible. In the short space of fourteen years they were completely cut out. The big mill closed down in the spring of 1909 , and by autumn the exodus from the town was in full swing. One of the hotels burned down in June, another in July. From then on sporadic fires were fairly common until in February, 1910, a whole block was destroyed. Thereupon the insurance companies cancelled all existing policies, and fires were replaced by a series of forced sales. Five-room frame houses with steam, water, and bath were offered for $\$ 25$, and sevenroom houses for $\$ 35$, without finding a buyer.

In the fall of 1913 the Buffalo and Susquehanna Railroad, which for some time had been running only three trains a week, discontinued its service entirely and the next spring tore up its rails. That was the coup de grâce. Cross Fork was dead. In five years both its population and the assessed value of its real estate had decreased by 98 per cent. The town had disappeared along with the forest on which its existence depended. Different management would have made possible a smaller but more permanent community.

In addition to industrial raw materials, people are indebted to forests for many other products and services. These include forage for livestock production; wildlife for the control of insect pests, the provision of food and fur, and the enjoyment of hunters, fishermen, and other lovers of the outdoors; water for irrigation, power, navigation, and municipal use; checking of floods; prevention of erosion; amelioration of climate; and op- 
portunities for physical rejuvenation and spiritual inspiration. It has been said that we could get along reasonably well without wood but not without forests. In spite of its exaggeration this statement contains an element of truth. Let me illustrate some of these other values, and the dangers to which improper forest management exposes them, by another story or two.

Trail Creek in central Colorado was originally a clear stream confined to a narrow channel and with comparatively little erosion. Gradually, however, the character of the stream changed as a result of heavy cutting and fires on the forested watershed where it rose. Floods became more frequent, erosion set in, the stream bed was widened, and its bottom began to fill up with sand and gravel washed down from above. In April, 1914, a heavy flood caused serious damage to a previously prosperous ranch at the mouth of the creek. Approximately a fourth of the irrigated land on the ranch was ruined by being buried under 18 to 30 inches of coarse gravel; the irrigation ditches were completely filled; and the course of the stream was so changed as to prevent the further use of water from it for irrigation. The next year another flood washed out several acres of hay land, ruined some 16 tons of hay, and piled gravel $2 \frac{1}{2}$ feet deep against the kitchen door.

Agriculture in central Utah is confined to a narrow strip of land which can be irrigated with water coming from the Wasatch Mountains immediately to the east. For 75 years the mountain water continued to be available with only minor irregularities in flow. Prosperous farms and communities developed. Then on August 13, 1923, came disaster. Thick, slimy mixtures of water, soil, and rock coming from several stecp canyons in Davis County swept everything before them. Houses were crushed like match boxes; orchards and crops were destroyed; farm lands were covered with mud, gravel, and boulders weighing as much as 200 tons. Six lives were lost and property damage ran into the hundreds of thousands of dollars.

Similar floods in subsequent years led to a thorough investigation which proved that they were due to the destruction of vegetation on steep slopes by fire and excessive grazing. Steps were promptly taken to control these destructive agencies, contour trenches were constructed to check surface runoff of water, and the denuded areas were seeded to perennial vegetation to help still further in reducing runoff and holding the soil in place. Two heavy rainfalls since these control measures were under- 
taken have resulted in practically no damage. People who inquired incredulously whether 200-ton boulders could be anchored by grass, brush, and trees have had their question answered in the affirmative.

On a prairie farm in western Kansas the owner was rapidly losing all of his fertile top soil by wind erosion. Crops were poor, living conditions uncomfortable. After every windstorm the housewife had to shovel the soil from the porch and sweep it from the interior of the house, while the county had to plow out an adjacent highway almost continuously in order to keep it open for travel. Today the picture is completely changed as a result of shelterbelt planting and consequent soil stabilization. Crops have improved, livestock is protected, wildlife has appeared, the outlook is more attractive, living in general is more comfortable.

Northern Michigan is a favorite mecca for tourists in large part because of its forests. When you or I decide to go automobiling, or camping, or picnicking, we ordinarily seek a place where there are trees to provide shelter and pleasant scenery. We like to cook our food over an open fire burning wood fuel that we have collected ourselves. And there is a quality about the forest that provides relaxation and inspiration for those who are weary in body or in spirit.

Possibly these various relationships between forests and people can be summed up in a bit of doggerel that I wrote some twenty years ago, with due apologies to numerous authors who have written in similar vein.

What do we plant when we plant a tree?

A thousand blessings for you and me-

We plant the lumber to build us a house,

We plant a cover to harbor the grouse;

We plant the fuel to kindle our fire,

When strikes the prices of coal send higher;

We plant for fences the posts and rails,

We plant a shelter to temper the gales.

We plant the pencils to scribble our notes,

We plant the ballots to cast our votes;

Ve plant the paper in which to read

The news that o'er wooden poles we speed.

We plant the piles to erect our docks,

We plant the rayon for shirts and socks;

We plant the extract to tan our shoes,

We plant 'most anything you choose!

We plant the barrel, the box, the crate,

In which to ship all sorts of freight; 


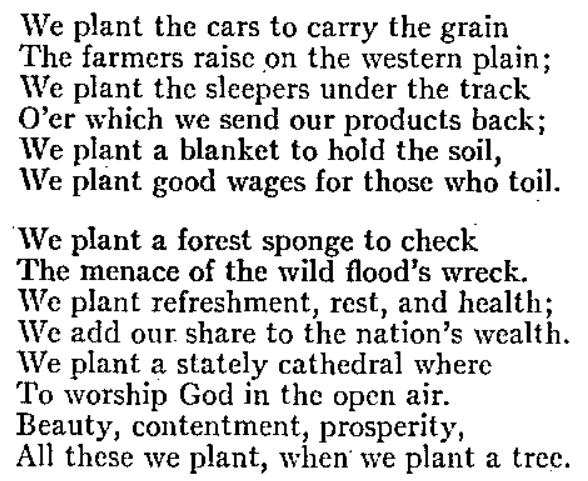

Now of course all these stories and verses have a moral. It is simply this: that if we are to continue to enjoy the products and services that forests have to offer, they must be so handled as to maintain their productivity. Since trees grow and reproduce themselves, this is entirely possible though by no means easy. Real effort is required, as is the case-in any worth-while undertaking, to protect, manage, and harvest the forest so that eàch new crop will be at least as good as that which preceded it. So far we have not succeeded in this country in attaining the kind of management that every one agrees to be desirable. Taken as a whole, the forests are still going downhill both in quantity and in quality.

You may be wondering what you personally can do about it. Probably most of you do not own any timberland and have no strong influence with any one who does. If that is the case, there are still three highly useful things that you can do. You can make sure that no forest is ever the worse for your presence in it; you can join with others in obtaining the adoption of satisfactory forest policies and forest practices; and you can arouse in the children whom you teach a determination to use their influence to sec to it that the forests continue permanently to play the part they should in the economic and social life of the nation.

Forest fires are still one of the greatest menaces to full forest productivity. Except for lightning, which is an important cause of fires in many parts of the West, they are due almost entirely to human carelessness, particularly on the part of tourists, campers, and smokers. The least you can do when in the woods is to make sure that no conflagration is caused by any match, cigarette, or camp fire over which you have control. And if you 
are considerate of others, you will see to it that the beauty of the forest is not marred by the indiscriminate cutting of trees and shrubs, the picking of rare flowers, or the scattering about of waste paper, tin cans, and other trash.

Experience throughout the world has demonstrated that government participation in the management of forest lands is essential if the interest that all of the people of a country obviously have in them is to be adequately safeguarded. That participation may take the form of public cooperation, public regulation, and public ownership. All of these activities, which may be on a national, state, or local level, have their place in any comprehensive program.

You can play an important part in the development of such a program by your support of policies that seem to you wise and your opposition to policies that you think unwise. Perhaps one of the best ways of keeping yourselves intelligently informed on the issues involved, and of making your influence most strongly felt, is through membership in one or more national or state organizations that are actively engaged in studies of the forest problem and in attempts to bring about its constructive solution. One of the most prominent of such organizations is the American Forestry Association, which has just completed a thoroughgoing appraisal of our forest resources and is now formulating a comprehensive forestry program for the nation.

Most of all you can render effective service by informing the children whom you teach of the numberless ways in which forests contribute to the well-being of the nation and of its individual citizens, and by arousing in them a desire to do their part in maintaining an adequate and permanent supply of forest products and services. The field is so broad that the opportunity to do so exists in connection with the teaching of almost any subject, including mathematics and the sciences. I can think of no phase of your work that in the long run is likely to yield larger dividends.

\section{A VACUUM CLEANER FOR THE CAR}

Vacuum cleaner, small enough to be kept in the glove compartment of an automobile, operates off the engine manifold vacuum when the car engine is run at idling speed. Connections are long enough to permit the use of the cleaner in any part of the car's interior. 